\title{
Isolation, characterization and application of theophylline-degrading Aspergillus fungi
}

\author{
Binxing Zhou ${ }^{1 *+}$, Cunqiang Ma ${ }^{1,2+}$, Tao Xia ${ }^{3}$, Xiaohong Li ${ }^{1}$, Chengqin Zheng ${ }^{1}$, Tingting Wu ${ }^{1}$ and Xiaohui Liu ${ }^{1}$
}

\begin{abstract}
Background: Caffeine, theobromine and theophylline are main purine alkaloid in tea. Theophylline is the downstream metabolite and it remains at a very low level in Camellia sinensis. In our previous study, Aspergillus sydowii could convert caffeine into theophylline in solid-state fermentation of pu-erh tea through $\mathrm{N}$-demethylation. In this study, tea-derived fungi caused theophylline degradation in the solid-state fermentation. The purpose of this study is identify and isolate theophylline-degrading fungi and investigate their application in production of methylxanthines with theophylline as feedstock through microbial conversion.

Results: Seven tea-derived fungi were collected and identified by ITS, $\beta$-tubulin and calmodulin gene sequences, Aspergillus ustus, Aspergillus tamarii, Aspergillus niger and A. sydowii associated with solid-state fermentation of pu-erh tea have shown ability to degrade theophylline in liquid culture. Particularly, A. ustus and A. tamarii could degrade theophylline highly significantly $(p<0.01)$. 1,3-dimethyluric acid, 3-methylxanthine, 3-methyluric acid, xanthine and uric acid were detected consecutively by HPLC in A. ustus and A. tamarii, respectively. The data from absolute quantification analysis suggested that 3-methylxanthine and xanthine were the main degraded metabolites in $A$. ustus and $A$. tamarii, respectively. $129.48 \pm 5.81 \mathrm{mg} / \mathrm{L}$ of 3-methylxanthine and $159.11 \pm 10.8 \mathrm{mg} / \mathrm{L}$ of xanthine were produced by A. ustus and A. tamarii in $300 \mathrm{mg} / \mathrm{L}$ of theophylline liquid medium, respectively.

Conclusions: For the first time, we confirmed that isolated A. ustus, A. tamarii degrade theophylline through N-demethylation and oxidation. We were able to biologically produce 3-methylxanthine and xanthine efficiently from theophylline through a new microbial synthesis platform with A. ustus and A. tamarii as appropriate starter strains.
\end{abstract}

Keywords: Aspergillus, Theophylline, 3-Methylxanthine, Bioconversion, Tea, Pathway

\section{Background}

Caffeine (1, 3, 7-trimethylxanthine) is the most abundant methylxanthine alkaloids in tea, and also one of the major tea flavor content causing bitterness [1]. Caffeine was extensively established to be the final mathylxanthine product biosynthesized through three steps of the methylation of xanthosine in the root of tea tree [2]. Until now, caffeine catabolism has been relatively understood and established in plants, mainly in tea

\footnotetext{
${ }^{*}$ Correspondence: bxzhou01@126.com

${ }^{\dagger}$ Binxing Zhou and Cunqiang Ma contributed equally to this work

${ }^{1}$ Long Run Pu-erh Tea College, Yunnan Agricultural University, Kunming 650201, Yunnan, China

Full list of author information is available at the end of the article
}

(Camellia sinensis) and caffeine (Coffea arabica) [3]. The major catabolic pathway of caffeine is as follows: caffeine $\rightarrow$ theobromine/theophylline $\rightarrow$ 3-methylxanthine $\rightarrow$ xanthine $\rightarrow$ uric $\quad$ acid $\rightarrow$ allantoin $\rightarrow$ allantoic acid $\rightarrow \mathrm{CO}_{2}+\mathrm{NH}_{3}[4,5]$. The other alternative catabolic pathways have been reported recently in Camellia plants $[6,7]$. Theophylline (1,3-dimethylxanthine) is a transient metabolite through the demethylation of caffeine at the position N-7 and stays a very low level due to the slow metabolism in tea leaves $[8,9]$.

Although caffeine level remains stable in the processing of general teas (green tea, black tea, oolong tea and white tea) [10, 11], several microorganisms selected from the soil of tea and coffee plantations could degrade 
caffeine, which included Pseudomonas sp. [12, 13], Pseudomonas putida [14, 15], Serratia marcescens, Fusarium solani $[16,17]$, Stemphyllium sp., Aspergillus tamarii, and Penicillium commune $[17,18]$. Two possible mechanisms of caffeine catabolism in microorganisms are $\mathrm{N}$-demethylation and oxidation [19]. Theophylline is the major metabolite formed in fungi through the $\mathrm{N}$-demethylation of caffeine, which present marked differences from bacteria that theobromine (3,7-dimethylxanthine) or paraxanthine (1,7-dimethylxanthine) are major metabolites in caffeine catabolism [13, 19]. Moreover, P. putida and Pseudomonas sp. were established to not only use caffeine, theobromine, paraxanthine (1,7-dimethylxanthine) and 7-methylxanthine, but also degrade theophylline and 3-methylxanthine [14, 20] (P. putida and Pseudomonas sp. were established to use caffeine, theobromine, paraxanthine (1,7-dimethylxanthine) and 7-methylxanthine, and they also degrade theophylline and 3-methylxanthine). In addition, Aspergillus niger, Talaromyces marneffei and Talaromyces verruculosus isolated from cocoa pod husks were established to degrade theobromine and produce methylxanthine [21]. However, only bacterial strain $P$. putida CBB5 was confirmed to degrade theophylline via $N$-demethylation $[14,22]$. Until now, the theophylline-degrading fungi and correlative metabolites were not completely definite.

$\mathrm{Pu}$-erh tea is one of the most representative dark tea and natural microorganisms involved in solid-state fermentation (SSF) play an important role in tea processing [23, 24]. Microorganisms including bacteria and fungi have profound impact on substance metabolisms and correlation with quality formation of pu-erh tea [25-27]. A. niger, Aspergillus tubingensis, Aspergillus fumigatus, Aspergillus acidus, Aspergillus awamori, A. tamarii, Blastobotrys adeninivorans, Candida tropicalis, Fusarium graminearum, Pichia farinosa, Rasamsonia byssochlamydoides, Rasamsonia emersonii, Rasamsonia cylindrospora, Rhizomucor pusillus, Rhizomucor tauricus and Thermomyces lanuginosus have been detected in pu-erh tea [28-31]. Theophylline has several applications in therapeutics, especially as anti-asthmatic, anticancer, anti-cellulite and combinatorial drug [32-34]. Caffeine content fluctuates during the SSF, which has associated with the fungi appearing in SSF [35-39]. We found that theophylline content was increased significantly $(\mathrm{p}<0.05)$ and Aspergillus sydowii caused caffeine degradation in SSF [40]. After further research, $A$. sydowii had a significant $(\mathrm{p}<0.05)$ impact on caffeine metabolism and potential value in theophylline production through aerobic fermentation $[41,42]$.

In this study, we found that theophylline content had a highly significant $(\mathrm{p}<0.01)$ decrease during the later period of SSF after a highly significant $(\mathrm{p}<0.01)$ increase.
Therefore, apart from an isolated caffeine-degrading fungus identified as $A$. sydowii causing the production of theophylline in SSF, theophylline-degrading fungi also could be found in SSF. In this paper, two theophyllinedegrading fungi were isolated from the SSF and identified as A. ustus and A. tamari based on colonial morphology and ITS, $\beta$-tubulin and calmodulin gene sequences, respectively. Theophylline degradation metabolites and pathways were analyzed in fungi by high-performance liquid chromatography (HPLC). The application in production of methylxanthines was investigated by using $A$. ustus and A. tamarii, respectively.

\section{Methods}

\section{Materials and reagents}

Sun-dried green tea leaves (C. sinensis var. assamica) with moisture content $6.25 \%$ by weight were obtained from Yunnan Province, China. Caffeine, theophylline, 3-methylxanthine, 1-methylxanthine, xanthine, 1,3-dimethyluric acid, 1-methyluric acid, 3-methyluric acid and uric acid were purchased from USA Sigma Company. SP fungal DNA kit was purchased from USA Omega Company. DNA marker, polymerase chain reaction (PCR) spread reagent, primers [43, 44]: ITS1 (5'-TCCGTAGGTGAA CCTGCGG- $3^{\prime}$ ) and ITS4 (5'-TCCTCCGCTTATTGA TAGC-3'); Bt2a (5'-GGTAACCAAATCGGTGCTGCT TTC-3') and Bt2b (5'-ACCCTCAGTGTAGTGACC CTTGGC- $3^{\prime}$ ); and CF1L (5'-GCTGACTCGTTGACC GAAGAG- $3^{\prime}$ ) and CF4 (5'-ATTTTTGCATCATGAGCT GAAC- $3^{\prime}$ ) were purchased from Japan TaKaRa Company. Other reagents were ether analytical grade or chromatographic grade.

\section{Pu-erh tea solid-state fermentation and determination of caffeine and theophylline}

The SSF of pu-erh tea was based on the natural microbiota existing on tea leaves and fermentation environment. A $2 \mathrm{~kg}$ sample of sun-dried green tea leaves was mixed with $885 \mathrm{~mL}$ tap water to achieve given moister content of $35 \%(\mathrm{w} / \mathrm{w})$ [30]. During the fermentation, tea leaves were mixed to ensure homogeneity and tap water was added to keep the appropriate moisture content at $25-35 \%$. The whole fermentation continued for about 35 days and samples were collected every 5 days. The colony forming units (CFU) were calculated by per gram of the dry weight after 2 days of cultivation at $30^{\circ} \mathrm{C}$. Caffeine and theophylline contents were determined by HPLC described by Zhou et al. [40, 41] using an Agilent 1200 series system and an Agilent $C_{18}$ Chromatogram column $(250 \mathrm{~mm} \times 4.6 \mathrm{~mm}, 5 \mu \mathrm{m})$. Samples collected on days 20 and 25 were stored at $4{ }^{\circ} \mathrm{C}$ and selected for further isolation and identification of theophylline-degrading fungi. 


\section{Fungal identification of isolates}

Fungal strains were isolated using potato dextrose agar (PDA) medium and they were counted by dilutionplating method [29]. Microscopic and morphological examinations of colonies were carried out according to mycological guide, and morphological features of their colonies are recorded in Table 1.

Fresh cells were obtained by centrifugation at $1700 \mathrm{~g}$ for 5 min after cultivation in $20 \mathrm{~mL}$ of Czapek Dox medium at $30{ }^{\circ} \mathrm{C}$ for 2 days on an incubator shaker $(250 \mathrm{rpm})$ and freeze-dried at $-80{ }^{\circ} \mathrm{C}[40,41]$. DNA was extracted by using SP fungal DNA kit. The fungal primers ITS1 and ITS4, Bt2a and Bt2b, and CF1L and CF4 were used in PCR to amplify ITS, $\beta$-tubulin and calmodulin regions, respectively [43]. The final volume of $50 \mu \mathrm{L}, 1.0 \mu \mathrm{L}$ of containing template DNA, $5 \mu \mathrm{L}$ of $10 \times$ buffer, $5 \mu \mathrm{L}$ of dNTPs $(2.5 \mathrm{mM}), 0.5 \mu \mathrm{L}$ of Taq polymerase, $1.0 \mu \mathrm{L}(10 \mu \mathrm{M})$ of each primer, and $36.5 \mu \mathrm{L}$ of sterile distilled water were used to implement amplifications [40, 41]. The PCR reaction procedure was as follows. Pre-degeneration at $95{ }^{\circ} \mathrm{C}$ for $5 \mathrm{~min}$, degeneration at $94{ }^{\circ} \mathrm{C}$ for $1 \mathrm{~min}$, annealing at $54{ }^{\circ} \mathrm{C}$ for $1 \mathrm{~min}$, extension at $72{ }^{\circ} \mathrm{C}$ for $1.5 \mathrm{~min}$, with 35 cycles, extension at $72{ }^{\circ} \mathrm{C}$ for $10 \mathrm{~min}$ [44]. It was stored at $10^{\circ} \mathrm{C}$ in the end of the reaction process.

The PCR was produced in an ABI3730 automatic DNA sequencer (Applied Biosystems, USA) [40]. The received sequences were sent to Genbank of NCBI to seek similar sequences of type strain by using Blastn [44]. Multiple sequence alignment was carried out by using Clustal $\mathrm{X}$ for Windows. The evolution distance was calculated through a Kimura2-parameter of the MEGA 4.0 Soft.

\section{Evaluation of growth of isolates in agar mediums}

The isolate strains were transferred into PDA medium and incubated aerobically at $30{ }^{\circ} \mathrm{C}$ for $72 \mathrm{~h}$ on an incubator shaker $(250 \mathrm{rpm})$, respectively. The spore suspension was adjusted to $1.0 \times 10^{7} \mathrm{CFU} / \mathrm{mL}$ for inoculation after eluting by using sterile saline solution. Qualitative screenings were carried out in Petri dishes containing a solid culture medium contained $20 \mathrm{~g} / \mathrm{L}$ agar, $4.0 \mathrm{~g} / \mathrm{L}$
$\mathrm{NaNO}_{3}, 1.3 \mathrm{~g} / \mathrm{L} \quad \mathrm{KH}_{2} \mathrm{PO}_{4}, 0.19 \mathrm{~g} / \mathrm{L} \quad \mathrm{Na}_{2} \mathrm{HPO}_{4} \cdot 7 \mathrm{H}_{2} \mathrm{O}$, $0.26 \mathrm{~g} / \mathrm{L} \mathrm{CaCl}{ }_{2} \cdot 2 \mathrm{H}_{2} \mathrm{O}, 0.19 \mathrm{~g} / \mathrm{L} \mathrm{MgSO}_{4}$ and $20 \mathrm{~g} / \mathrm{L}$ dextrose as carbon source (control culture) or a selection medium with theophylline instead of dextrose in three different concentrations: 600, 1200 and $1800 \mathrm{mg} / \mathrm{L}$ per plate, respectively [40]. Fungal spore suspensions were transferred to the surfaces of the agar plates with an inoculating loop $(10 \mu \mathrm{L})$. Isolates were incubated at $30^{\circ} \mathrm{C}$ for 5 days. Compared with the control culture, theophylline utilization capacity of isolates was estimated by the size of the colony grown on the plates (Table 3).

\section{Assessment of theophylline-degrading fungi in different theophylline liquid mediums}

Theophylline liquid medium (TLM) was prepared using $4.0 \mathrm{~g} / \mathrm{L} \quad \mathrm{NaNO}_{3}, 1.3 \mathrm{~g} / \mathrm{L} \quad \mathrm{KH}_{2} \mathrm{PO}_{4}, 0.19 \mathrm{~g} / \mathrm{L}$ $\mathrm{Na}_{2} \mathrm{HPO}_{4} \cdot 7 \mathrm{H}_{2} \mathrm{O}, 0.26 \mathrm{~g} / \mathrm{L} \mathrm{CaCl}_{2} \cdot 2 \mathrm{H}_{2} \mathrm{O}, 0.15 \mathrm{~g} / \mathrm{L} \mathrm{MgSO}$, $2.0 \mathrm{~g} / \mathrm{L}$ sucrose and $300 \mathrm{mg} / \mathrm{L}$ theophylline in distilled water [45]. To investigate the influence of carbon and nitrogen source on theophylline degradation, the modifications used either $5 \mathrm{~g} / \mathrm{L}$ sucrose or $10 \mathrm{~g} / \mathrm{L}$ dextrose as carbon source in TLM with sucrose as carbon source (TLM-S) or TLM with dextrose as carbon source (TLMD), and $1.01 \mathrm{~g} / \mathrm{L}$ ammonium sulphate as nitrogen source in TLM with ammonium sulphate as nitrogen source (TLM-N), and $5 \mathrm{~g} / \mathrm{L}$ sucrose and $1.01 \mathrm{~g} / \mathrm{L}$ ammonium sulphate in TLM with sucrose and ammonium sulphate as carbon and nitrogen sources (TLM-SN), respectively. The spore suspension was adjusted to $1.0 \times 10^{7} \mathrm{CFU} / \mathrm{mL}$ and all given TLM was adjusted for $\mathrm{pH} 6.0$ by phosphate buffer before inoculation. For each isolate, control and experimental mediums ( $25 \mathrm{~mL}$ each) were inoculated with spore suspension with $4 \%$ inoculum size $(\mathrm{v} / \mathrm{v})$ that $1 \mathrm{~mL}$ spore suspension was inoculated into each medium, and biocidal treatment was defined as the control. Theophylline concentration was determined and mycelium was collected after cultivation at $30{ }^{\circ} \mathrm{C}$ for 5 days on an incubator shaker (130 rpm), respectively. The collected mycelium was filtered in a Buchner funnel, and rinsed in $20 \mathrm{~mL}$ of water: ethyl acetate (1:1) [46]. The mycelial mass

Table 1 Colony characteristics of theophylline-degrading fungi

\begin{tabular}{|c|c|c|c|c|c|}
\hline Isolate & Shape & Surface & Color & Exudates & References \\
\hline PT-1 & Circular & Rough & Black & None & [40] \\
\hline PT-2 & Circular & Rough & Olive green & Red-coloured & {$[40]$} \\
\hline PT-3 & Circular & Rough & Dark yellow colonies with white edges & Yellow sclerotium & [41] \\
\hline PT-4 & Irregular & Rough & Light yellow & Yellow sclerotium & [41] \\
\hline PT-5 & Circular & Rough & Greyish-green centre with yellow patches & Red pigment & [41] \\
\hline PT-6 & Circular & Rough & Iron gray bulge with milk white edges & None & Additional file 1: Figure S1 \\
\hline PT-7 & Irregular & Rough & Hazel green with gray back & None & Additional file 1: Figure S2 \\
\hline
\end{tabular}


was determined as fungal dry mass after drying at $35^{\circ} \mathrm{C}$ for $24 \mathrm{~h}$ and results were summarized in Additional file 2: Table S1 [46]. Theophylline concentration was determined by HPLC [21].

\section{Analysis of theophylline degradation metabolites by selected isolates}

Through comparison, additional sucrose could promote theophylline degradation in liquid culture. Therefore, TLM-S was selected as the optimal medium to analyze theophylline degradation by selected isolates. A series of TLM-S mediums with different initial theophylline concentrations $(100,200$ and $300 \mathrm{mg} / \mathrm{L}$, respectively) were set up each day of incubation and a 7-day period cultivation of each selected isolates were carried out on an incubator shaker $\left(130 \mathrm{rpm}, 30^{\circ} \mathrm{C}\right)$. At intervals of up to $24 \mathrm{~h}$ for 7 days, an aliquot of each culture was filtered through a $0.45 \mu \mathrm{m}$ syringe filter, and theophylline concentration and related metabolites were determined by HPLC according to the method from Mensah et al. [21].

Standard calibration curves were prepared from solutions of theophylline, 3-methylxanthine, 1-methylxanthine, xanthine, 1,3-dimethyluric acid, 1-methyluric acid, 3-methyluric acid and uric acid. $2 \mathrm{~mL}$ aliquots from each collected culture were filtered and analyzed by HPLC for theophylline, 3-methylxanthine, 1-methylxanthine, xanthine, 1,3-dimethyluric acid, 1-methyluric acid, 3-methyluric acid and uric acid. Internal standard method was used to aid in identification of metabolites. The concentrations of main degradation products (3-methylxanthine and xanthine) were analyzed in inoculated culture medium by selected isolates.

\section{Influence of selected isolates on 3-methylxanthine and xanthine}

Analysis of theophylline degradation metabolites showed that $\mathrm{N}$-demethylation was the main theophylline degradation pathway in fungi, and 3-methylxanthine and xanthine were main demethylated products. To explore the effects of selected isolates on 3-methylxanthine and xanthine, 3-methylxanthine and xanthine liquid mediums were prepared as above described with $5 \mathrm{~g} / \mathrm{L}$ sucrose as carbon source and $100 \mathrm{mg} / \mathrm{L}$ 3-methylxanthine or $100 \mathrm{mg} / \mathrm{L}$ xanthine, respectively. Each isolate was inoculated with $4 \%$ inoculum size $(\mathrm{v} / \mathrm{v})$ and biocidal treatment was defined as the control. 3-Methylxanthine and xanthine concentrations were determined by HPLC after cultivation at $30{ }^{\circ} \mathrm{C}$ for 5 days on an incubator shaker (130 rpm), respectively.

\section{Statistical analysis}

Three biological replications were carried out to ensure validity and repeatability. All data are presented as mean value \pm standard deviation (SD). One-way analysis of variance (one-way ANOVA) was carried out by Duncan's multiple-range test using SPSS 20.0 for window to determine whether the significant difference at $\mathrm{p}<0.05$ level or the highly significant difference in $\mathrm{p}<0.01$ level exist.

\section{Results \\ Theophylline degradation exists in solid-state fermentation of pu-erh tea}

Fungi count, caffeine and theophylline contents were determined in natural SSF of pu-erh tea, and results are presented in Fig. 1. Fungi count (Fig. 1a) dramatically increased from day 0 to 10 and then increased slowly before day 20. After day 20, fungi count maintained a high level overt $1.0 \times 10^{5} \mathrm{CFU} / \mathrm{g}$. Because of the metabolic activity of fungi, caffeine content (Fig. 1b) was decreased highly significantly $(\mathrm{p}<0.01)$ from $36.85 \pm 1.02$ to $25.46 \pm 1.85 \mathrm{mg} / \mathrm{g}$ during fermentation. Theophylline content (Fig. 1c) was increased highly significantly ( $\mathrm{p}<0.01$ ) before day 20, which confirmed that caffeinedegrading fungi leaded to caffeine degradation and theophylline production. However, after day 20, theophylline content had a highly significant $(\mathrm{p}<0.01)$ decrease from $11.18 \pm 1.10$ to $5.89 \pm 0.65 \mathrm{mg} / \mathrm{g}$, showing that theophylline degradation appeared in SSF except for caffeine degradation. Therefore, in consideration of fungal community, there are theophylline-degrading fungi in the SSF, which could be $A$. sydowii or other fungi.

\section{Isolation and identification of theophylline-degrading fungi}

Based on colony morphology, eleven filamentous fungi were initially selected and isolated from the SSF of puerh tea. Among them, seven fungi were superior in number and coded orderly with numbers PT-1 to PT-7. Distinctive morphological features of the seven isolates were observed after cultivation at $30{ }^{\circ} \mathrm{C}$ for 5 days and documented in Table 1.

The sequences obtained from the pure isolate in this study were deposited in GenBank under the accession number from MT065763 to MT065769 and from MT084116 to MT064123. Based on the DNA sequences in Table 2 and Additional file 1: Figures S3, S4, seven dominating isolates were belonged to 6 Aspergillus spp. and 1 Penicillium sp., respectively. Through neighborjoining analysis in the phylogram for Aspergillus species (Additional file 1: Figures S5a, b), strain PT-6 was clustered with $A$. ustus and showed a $100 \%$ of identity to the tested A. ustus NRRL275; additionally, strain PT-7 was closely related to $A$. tamarii NRRL20818 with $99.9 \%$ of identity. In general, those seven candidate isolates were identified as $A$. niger, A. sydowii, Aspergillus pallidofulvus, Aspergillus sesamicola, Penicillium manginii, A. 

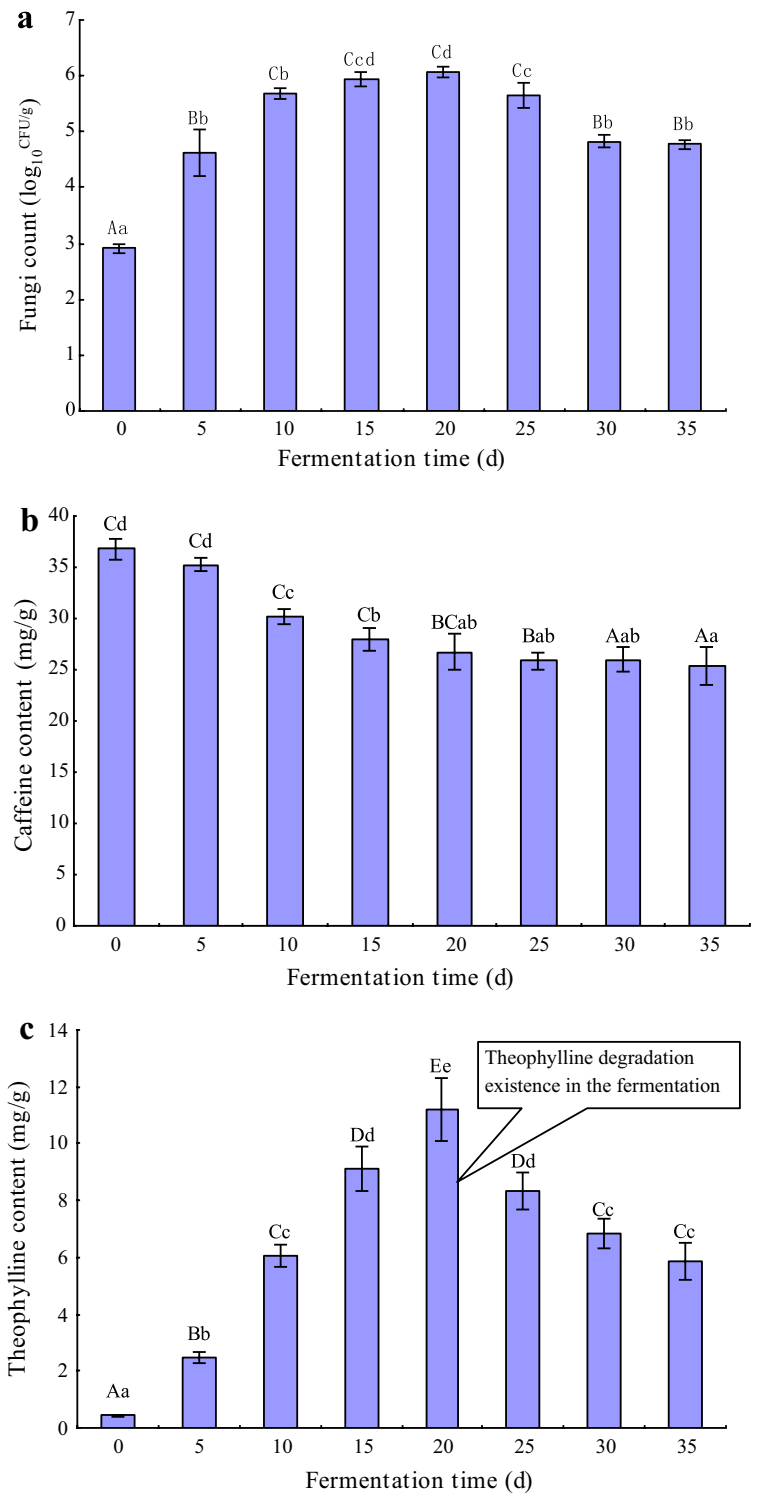

Fig. 1 Changes of fungi count (a), caffeine content (b) and theophylline content (c) during the solid-state fermentation of pu-erh tea. All data were present by mean value \pm SD of three replications. The lowercase letters indicated a significant difference at $p<0.05$ levels and the uppercase letters indicated a highly significant difference at $p<0.01$ levels using one-way ANOVA of SPSS 20.0. The different letters show significant differences

ustus and A. tamarii based on their morphological features and amplified sequences, respectively.

\section{Evaluation results of theophylline-degrading fungi in solid mediums}

The screening was carried out in agar solid mediums for the evaluation of the biocatalytic potential in theophylline degradation. All isolate tea-derived strains were inoculated into an agar solid medium with the presence of dextrose and they were also inoculated into a set of agar solid mediums with increasing theophylline concentrations. The colony diameters of potential theophylline-degrading fungi were measured and showed in Table 3.

Six isolates could survive in the agar solid mediums $(2 \% \mathrm{w} / \mathrm{v})$ with theophylline. Aspergillus spp. showed a better growth in higher evaluated concentrations. Particularly, A. niger, A. sydowii, A. ustus and A. tamarii had growth in low theophylline concentration, which showed that these strains had a high utilization ratio of theophylline as carbon source directly $[40,46]$. Therefore, A. niger, A. sydowii, A. ustus and A. tamarii were considered as potential theophylline-degrading fungi.

\section{Selection of theophylline-degrading fungi and optimal medium in liquid culture}

For theophylline biodegradation in liquid culture, seven isolates were inoculated into TLM with the presence of theophylline and sucrose or dextrose as carbon source, or ammonium sulphate as nitrogen source, respectively. Theophylline concentration and fungal dry mass were determined after cultivation at $30{ }^{\circ} \mathrm{C}$ for 5 days. Results are showed in Fig. 2 and Additional file 2: Table S1, respectively. Through comparisons of each isolate, with the presence of carbon source such as sucrose or dextrose, although all isolates could survive and maintain metabolic activity in TLM, theophylline utilization efficiency was different. A. pallidofulvus, A. sesamicola and $P$. mangini had no ability to use theophylline. Theophylline utilization of $A$. niger and $A$. sydowii was restricted in liquid culture, theophylline removal ratios were about $1.03 \%$ and $5.19 \%$ in TLM-S, respectively. Only A. ustus and A. tamarii could utilize caffeine significantly in all given TLM. Hence, $A$. ustus, A. tamarii, $A$. niger and $A$. sydowii were potential theophyllinedegrading fungi for theophylline degradation in liquid culture.

The presence of additional carbon or nitrogen sources had a significant impact on theophylline degradation and pathway. The optimum liquid medium was chose by comparing theophylline removal ratios in different mediums. In contrast with other mediums (TLM$\mathrm{D}$, TLM-N and TLM-SN), theophylline degradation level had a highly significant $(\mathrm{p}<0.01)$ improvement in TLM-S. In addition, extra sucrose promoted theophylline degradation in TLM-S inoculated by A. ustus and $A$. tamarii through enhancing cell density in liquid culture. Therefore, TLM-S was selected to analyze characterization of theophylline degradation in liquid culture. 
Table 2 Identification of theophylline-degrading fungi by sequence determination

\begin{tabular}{|c|c|c|c|c|c|c|}
\hline Isolate & Primers & Fragments (bp) & Accession number ${ }^{a}$ & Species & Strain number & Identity (\%) \\
\hline PT-1 & ITS1/ITS4 & 546 & MT065763 & Aspergillus niger & NCBT 110A & 99.8 \\
\hline PT-2 & ITS1/ITS4 & 516 & МT065764 & Aspergillus sydowii & NRRL 250 & 99.8 \\
\hline \multirow[t]{3}{*}{ PT-3 } & ITS1/ITS4 & 541 & МT065765 & Aspergillus pallidofulvus & NRRL 4789 & 99.9 \\
\hline & $\mathrm{Bt} 2 \mathrm{a} / \mathrm{Bt} 2 \mathrm{~b}$ & 516 & MT084116 & & & \\
\hline & CF1L/CF4 & 765 & МT084120 & & & \\
\hline \multirow[t]{3}{*}{ PT-4 } & ITS1/ITS4 & 532 & МT065766 & Aspergillus sesamicola & CBS 137324 & 99.8 \\
\hline & $\mathrm{Bt} 2 \mathrm{a} / \mathrm{Bt} 2 \mathrm{~b}$ & 515 & МT084117 & & & \\
\hline & CF1L/CF4 & 757 & МT084121 & & & \\
\hline \multirow[t]{2}{*}{ PT-5 } & ITS1/ITS4 & 525 & МT065767 & Penicillium manginii & CBS 253.31 & 99.6 \\
\hline & $\mathrm{Bt} 2 \mathrm{a} / \mathrm{Bt} 2 \mathrm{~b}$ & 420 & MT084118 & & & \\
\hline \multirow[t]{2}{*}{ PT-6 } & ITS1/ITS4 & 502 & МT065768 & Aspergillus ustus & NRRL 275 & 100 \\
\hline & CF1L/CF4 & 694 & MT084122 & & & \\
\hline \multirow[t]{3}{*}{ PT-7 } & ITS1/ITS4 & 532 & МT065769 & Aspergillus tamarii & NRRL 20818 & 99.9 \\
\hline & $\mathrm{Bt} 2 \mathrm{a} / \mathrm{Bt} 2 \mathrm{~b}$ & 476 & MT084119 & & & \\
\hline & CF1L/CF4 & 715 & MT084123 & & & \\
\hline
\end{tabular}

a GenBank/EMBL/DDBJ accession number

Table 3 Growth of tea-derived fungi in agar solid medium $(2 \% \mathrm{w} / \mathrm{v})$ with dextrose $(2 \% \mathrm{w} / \mathrm{v})$ (control culture) or presence of theophylline instead of dextrose $\left(30^{\circ} \mathrm{C}, 5 \mathrm{~d}, \mathrm{pH} 7.0\right)$

\begin{tabular}{|c|c|c|c|c|}
\hline \multirow[t]{2}{*}{ Isolate fungi } & \multicolumn{4}{|c|}{ Colony diameter $(\mathrm{cm})$} \\
\hline & Control culture & $600 \mathrm{mg} / \mathrm{L}$ theophylline & $1200 \mathrm{mg} / \mathrm{L}$ theophylline & $\begin{array}{l}1800 \mathrm{mg} / \mathrm{L} \\
\text { theophylline }\end{array}$ \\
\hline A. niger & $3.5 \pm 0.5$ & $0.5 \pm 0.2$ & No growth & $1.0 \pm 0.5$ \\
\hline A. sydowii & $2.5 \pm 1.0$ & $0.5 \pm 0.1$ & $1.0 \pm 0.3$ & $0.5 \pm 0.3$ \\
\hline A. pallidofulvus & $3.0 \pm 0.5$ & No growth & No growth & $0.5 \pm 0.1$ \\
\hline A. sesamicola & $3.0 \pm 0.5$ & No growth & No growth & $0.5 \pm 0.1$ \\
\hline P. mangini & $3.0 \pm 1.0$ & No growth & No growth & No growth \\
\hline A. ustus & $2.5 \pm 0.5$ & $1.0 \pm 0.3$ & $1.5 \pm 0.4$ & $1.5 \pm 0.4$ \\
\hline A. tamarii & $3.0 \pm 0.5$ & $2.0 \pm 0.5$ & $2.5 \pm 0.5$ & $3.5 \pm 1.0$ \\
\hline
\end{tabular}

\section{Characterization of theophylline degradation inoculated} by theophylline-degrading fungi

Aspergillus ustus, A. tamarii, A. niger and A. sydowii were inoculated into TLM-S with increasing theophylline concentrations (100, 200 and $300 \mathrm{mg} / \mathrm{L}$, respectively), and Tissue-culture bottles were incubated in an orbital shaker $\left(130 \mathrm{rpm}, 30{ }^{\circ} \mathrm{C}\right)$. The inoculation bottles were took every $24 \mathrm{~h}$ for the determination of theophylline and related metabolites by HPLC, and results are presented in Fig. 3. Under effects of $A$. ustus and $A$. tamarii, theophylline decreased highly significantly $(\mathrm{p}<0.01)$ in all substrate concentrations. However, theophylline decreased slightly ( $\mathrm{p}>0.05)$ in all concentrations inoculated by $A$. niger and A. sydowii. Therefore, A. ustus and A. tamarii had more advantage in theophylline degradation than $A$. niger and A. sydowii. Both $A$. ustus and A. tamarii could degrade theophylline completely in low concentration $(100 \mathrm{mg} / \mathrm{L}$ theophylline). However, A. ustus only degrade $79.00 \%$ theophylline in high concentration $(300 \mathrm{mg} / \mathrm{L}$ theophylline), while $A$. tamarii could degrade theophylline almost completely in all given concentrations, which showed that $A$. tamarii had a higher theophylline degradation capacity.

A series of experiments was conducted to find out theophylline degradation pathway through the identification of catabolic intermediates by HPLC using internal standard method (Table 4). 1,3-Dimethyluric acid, 3-methylxanthine, 3-methyluric acid, xanthine and uric acid were detected consecutively in the liquid culture. 3-Methylxanthine was common and main metabolite through $N$-demethylation at the position $\mathrm{N}-1$ of theophylline in A. ustus and A. tamarii. Xanthine was a further demethylated metabolite in theophylline degradation found in A. ustus and $A$. tamarii through $N$-demethylation at the 

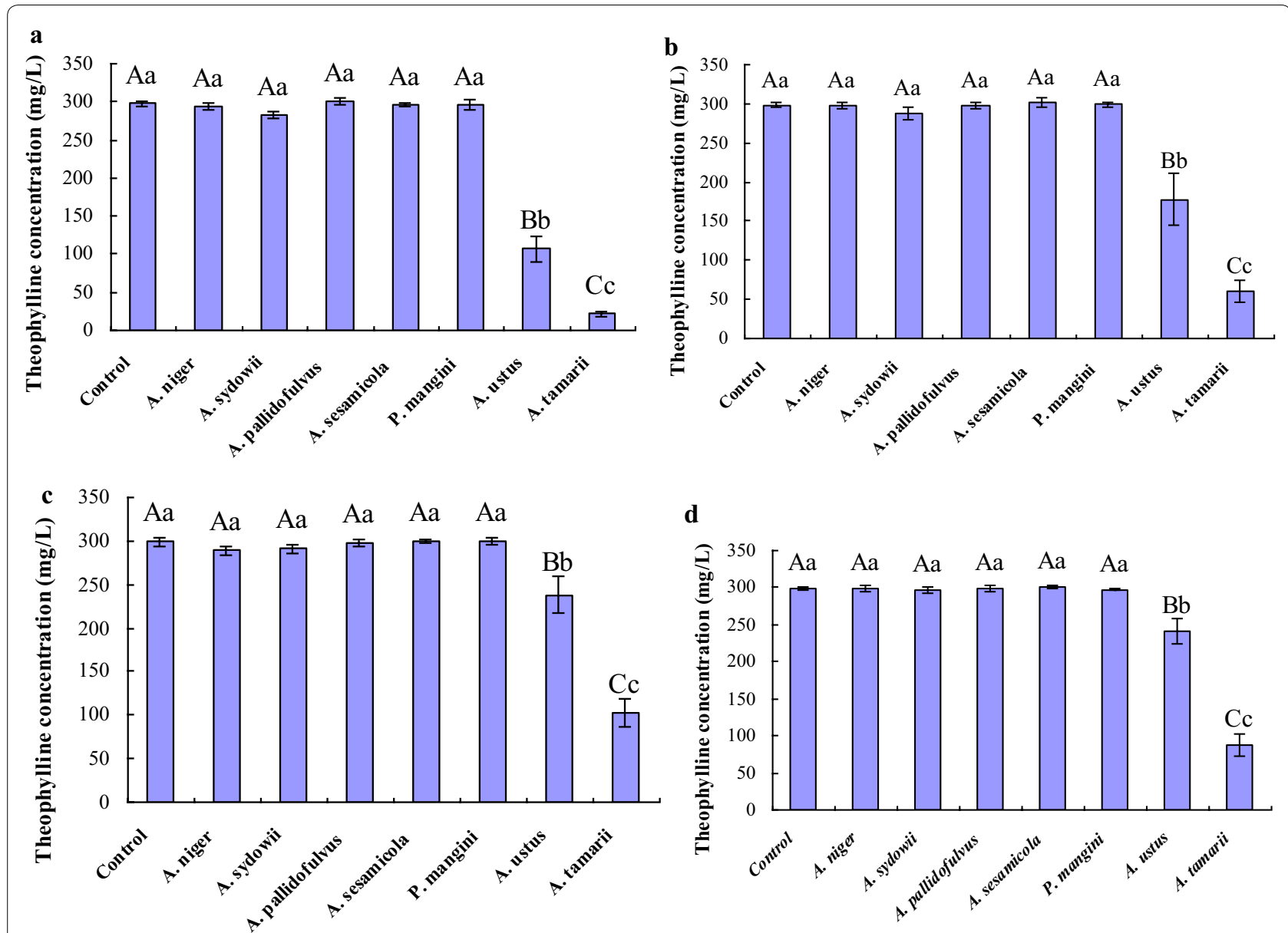

Fig. 2 Theophylline degradation capacity of isolate fungi strains in different theophylline liquid mediums. a TLM-S theophylline liquid medium with sucrose as carbon source; $\mathbf{b} T L M-D$ theophylline liquid medium with dextrose with sucrose as carbon source; $\mathbf{c} T L M-N$ theophylline liquid medium with ammonium sulphate as nitrogen source; $\mathbf{d}$ TLM-SN theophylline liquid medium with sucrose and ammonium sulphate as carbon and nitrogen sources, respectively. Biocidal treatment was defined as the control. All data were present by mean value \pm SD of three replications. The lowercase letters indicated a significant difference at $p<0.05$ levels and the uppercase letters indicated a highly significant difference at $p<0.01$ levels using one-way ANOVA of SPSS 20.0. The different letters show significant differences

position N-3 of 3-methylxanthine. In contrast to A. ustus that additional metabolites including 1,3-dimethyluric acid and 3-methyluric acid were identified in the culture through the oxidation of theophylline and 3-methylxanthine, respectively, only uric acid was identified in A. tamarii culture as the oxidation product of xanthine, which showed the differences in degradation metabolites and pathways between $A$. ustus and A. tamarii.

\section{Production of 3-methylxanthine or xanthine through theophylline degradation}

Several xanthine derivatives including 3-methylxanthine have been synthesized chemically for use in medical industry [47]. Except for engineering a microbial platform for de novo biosynthesis of diverse methylxanthins [48], bioconversion from cheaper feedstocks such as caffeine, theophylline and theobromine was an effective pathway to produce high value methylxanthines via metabolically engineered microorganisms [22]. In this study, 3-methylxanthine and xanthine were common and main products in theophylline degradation by A. ustus and A. tamarii. Microbial utilization of 3-methylxanthine and xanthine were investigated in liquid culture of isolates. 3-Methylxanthine and xanthine concentrations were determined by HPLC after cultivation for 5 days. As shown in Fig. 4, A. ustus and A. tamarii had a significant $(\mathrm{p}<0.05)$ or a highly significant $(\mathrm{p}<0.01)$ impact on 3-methylxanthine degradation with a removal ratio of about $27.05 \%$ and $84.29 \%$, respectively. Additionally, A. tamarii had a highly significant $(\mathrm{p}<0.01)$ impact on xanthine degradation with a removal ratio of about $51.77 \%$. Associated with the metabolites detected in theophylline degradation, 3-methyluric acid and xanthine were 3-methylxanthine 

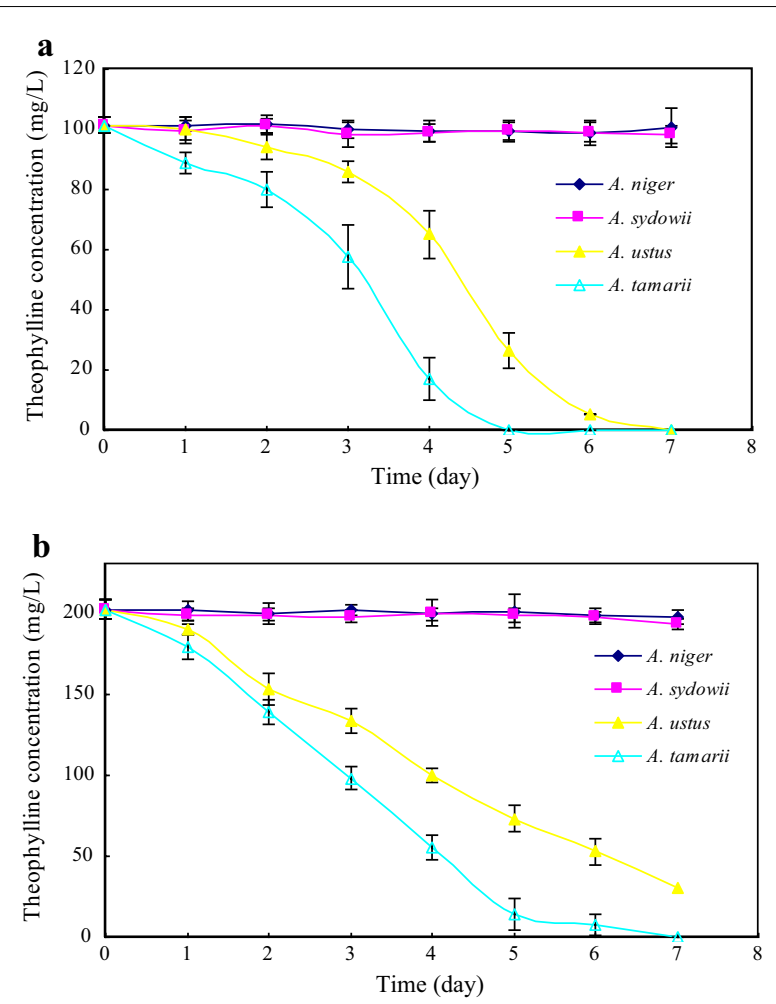

c

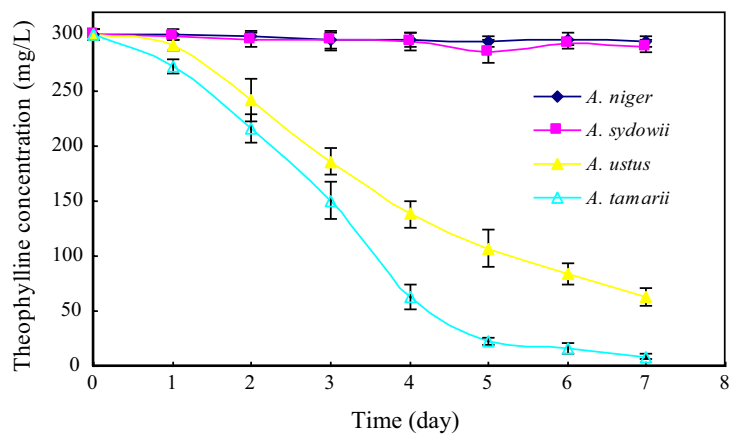

Fig. 3 Effects of potential theophylline-degrading fungi on theophylline catabolism in different substrate concentrations. Theophylline concentrations were $100 \mathrm{mg} / \mathrm{L}$ (a), $200 \mathrm{mg} / \mathrm{L}$ (b), and $300 \mathrm{mg} / \mathrm{L}$ (c), respectively. All data were present by mean value \pm SD of three replications

degradation metabolites through oxidation and $\mathrm{N}$-demethylation, respectively.

Despite of significant impacts on 3-methylxanthine and xanthine degradation, 3-methylxanthine and xanthine concentrations were accumulated largely in TLM-S inoculated by $A$. ustus and A. tamarii, respectively. To investigate the application in production of 3-methylxanthine and xanthine by using theophylline-degrading fungi with theophylline as feedstock, quantitative determinations of 3-methylxanthine and xanthine were carried out in all theophylline
Table 4 Theophylline degradation metabolites detected in the liquid culture inoculated by Aspergillus fungi

\begin{tabular}{lllll}
\hline Metabolite & \multicolumn{4}{l}{ Fungal isolates } \\
\cline { 2 - 5 } & A. ustus & A. tamarii & A. niger & A. sydowii \\
\hline 1,3-Dimethyluric acid & + & - & - & - \\
1-Methylxanthine & - & - & - & - \\
3-Methylxanthine & + & + & - & - \\
1-Methyluric acid & - & - & - & - \\
3-Methyluric acid & + & - & - & - \\
Xanthine & + & + & - & - \\
Uric acid & - & + & - & -
\end{tabular}

TLM-S inoculated by Aspergillus fungi were analyzed by HPLC for

1,3-dimethyluric acid, 1-methylxanthine, 3-methylxanthine, 1-methyluric acid, 3-methyluric acid, xanthine and uric acid

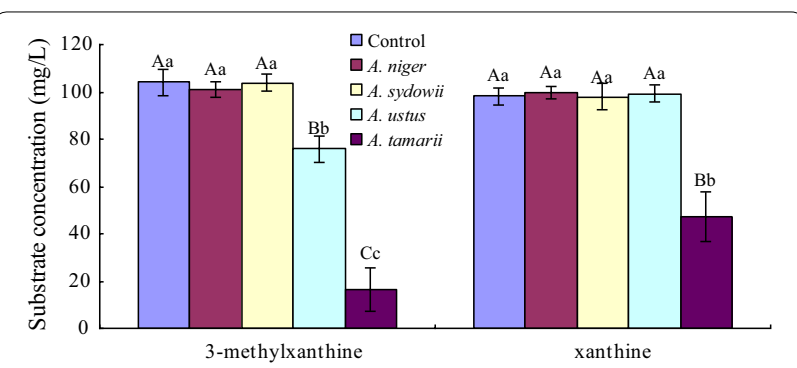

Fig. 4 Effects of potential theophylline-degrading fungi on 3-methylxanthine and xanthine, respectively. Biocidal treatment was defined as the control. All data were present by mean value \pm SD of three replications. The lowercase letters indicated a significant difference at $p<0.05$ levels and the uppercase letters indicated a highly significant difference at $p<0.01$ levels using one-way ANOVA of SPSS 20.0. The different letters show significant differences

concentrations inoculated by A. ustus and A. tama$r i$, respectively. 3-Methylxanthine and xanthine concentrations in $A$. ustus and $A$. tamarii cultures are presented in Fig. 5. We monitored the accumulation of 3-methylxanthine and xanthine over the course of inoculated culture by A. ustus and A. tamarii. 3-Methylxanthine was detected in the culture medium after $24 \mathrm{~h}$ for the first time, and increased significantly with cultivation. Over a 7-day period cultivation of A. ustus (Fig. 5a), $49.68 \pm 2.97 \mathrm{mg} / \mathrm{L}, 83.82 \pm 3.35 \mathrm{mg} / \mathrm{L}$ and $129.48 \pm 5.81 \mathrm{mg} / \mathrm{L}$ of 3-methylxanthine were accumulated and increased significantly with increasing initial theophylline concentrations, respectively. Due to high degradation capacity of 3-methylxanthine in A. tamarii culture, 3-methylxanthine concentration (Fig. 5b) stayed at a low level that only $56.72 \pm 5.81 \mathrm{mg} / \mathrm{L}$ of 3 -methylxanthine was accumulated in $300 \mathrm{mg} / \mathrm{L}$ of theophylline after a 7-day period cultivation. Hence, $A$. ustus exhibited a continuing accumulation of 3-methylxanthine over the course of liquid culture, and 

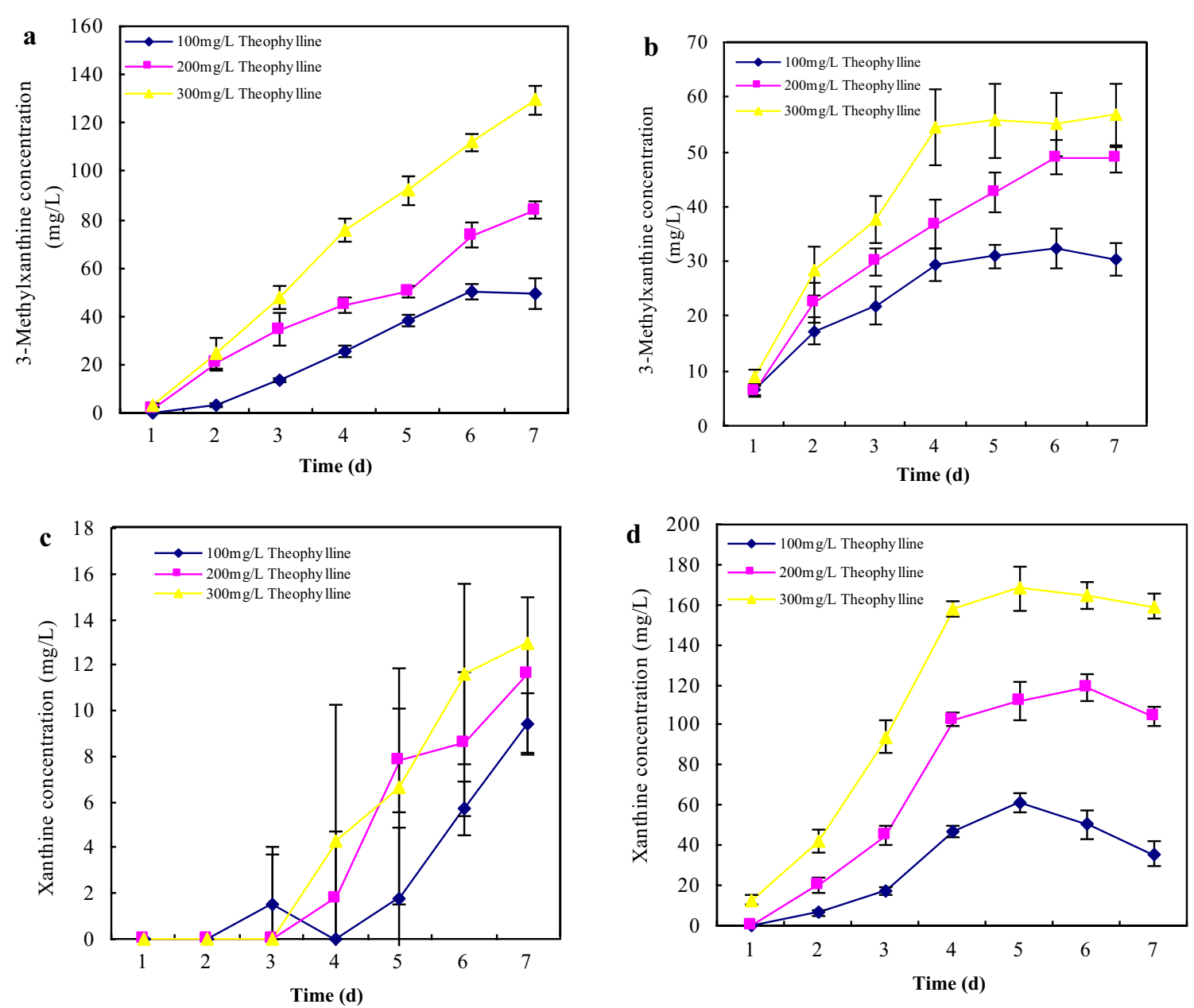

Fig. 5 Effects of theophylline concentrations on 3-methylxanthine production $(\mathbf{a}, \mathbf{b})$ and xanthine production (c, $\mathbf{d})$ by theophylline-degrading fungi. Liquid culture assays were performed using TLM-S with different theophylline concentrations inoculated by Aspergillus ustus (a, c) and Aspergillus tamarii (b, d), respectively. Theophylline concentrations were $100 \mathrm{mg} / \mathrm{L}$ (filled rhombus), $200 \mathrm{mg} / \mathrm{L}$ (filled square), and $300 \mathrm{mg} / \mathrm{L}$ (filled triangle). Concentrations of 3-methylxanthine were present by mean value \pm standard deviations (SD) of three replications

increasing initial theophylline concentrations could improve the production of 3-methylxanthine.

Xanthine concentration over a 7-day period cultivation of A. ustus (Fig. 5c) maintained at a low level below $15.00 \mathrm{mg} / \mathrm{L}$ in all substrate concentrations. However, Fig. $5 \mathrm{~d}$ showed a reaction containing theophylline in A. tamarii culture provided linear conversion of theophylline to xanthine. Over a 7-day period cultivation of A. tamarii, $35.88 \pm 6.65 \mathrm{mg} / \mathrm{L}, 103.95 \pm 4.82 \mathrm{mg} / \mathrm{L}$ and $159.11 \pm 10.8 \mathrm{mg} / \mathrm{L}$ of xanthine were accumulated and increased significantly with increasing initial theophylline concentrations through $\mathrm{N}$-demethylation at the position N-3 of 3-methylxanthine, respectively. Therefore, xanthine was main metabolite in theophylline degradation over the course of $A$. tamarii liquid culture, which showed that $A$. tamarii could be used for the production of xanthine with theophylline as feedstock through microbial conversion.

\section{Discussion}

Although caffeine and related methylxanthines are toxic to most bacteria and invertebrates [49], some bacteria and fungi have evolved the ability to metabolize caffeine [12, 16]. In our previous studies [40-42], caffeine content was decreased significantly, and $A$. sydowii leaded to caffeine degradation and converted the most degraded caffeine to theophylline. In this study, we confirmed a new phenomenon (Fig. 1) that theophylline degradation was found in SSF of pu-erh tea. This suggested that potential theophylline-degrading fungi could be found in fungal community.

Molecular identification of fungi is mostly dependent on PCR amplified sequences of ITS, $\beta$-tubulin and 
calmodulin genes, particularly the genera Aspergillus and Penicillium [50, 51]. The amplified sequencing and colony morphology indicated that their seven candidate isolates were identified specifically as A. niger, A. sydowii, A. pallidofulvus, A. ustus, A. sesamicola, A. tamarii and $P$. mangini, respectively. This was in line with the observation in literature that Aspergillus spp. and Penicillium spp. are the filamentous fungal genera commonly associated with SSF of pu-erh tea [52-54], particularly A. niger, A. sydowii and $A$. tamarii having been widely reported as the dominant fungi in the SSF of pu-erh tea.

The assessment in agar mediums with theophylline as carbon source showed that six Aspergillus isolates could survive in theophylline agar mediums, which suggested that those six candidate isolates (Table 3) could utilize theophylline as potential carbon source directly in the absence of other carbon source. The data from the liquid culture inoculated by seven isolates indicated that $A$. ustus and $A$. tamarii could degrade theophylline significantly $(\mathrm{p}<0.05)$ or highly significantly $(\mathrm{p}<0.01)$; moreover, the theophylline utilization of $A$. niger and A. sydowii were restricted. However, at the presence of sucrose as carbon source in liquid culture, A. pallidofulvus, A. sesamicola and $P$. mangini had no ability to use theophylline. Though the effect of $\mathrm{C} / \mathrm{N}$ ratio on growth is strain-dependent [55], increasing $\mathrm{C} / \mathrm{N}$ ratio would generally favour fungal growth, which influenced microbial metabolism to a certain degree. Through comparisons of theophylline degradation capacity in different TLM containing sucrose or dextrose as carbon source, or ammonium sulphate as nitrogen source, sucrose enhanced theophylline degradation highly significantly $(\mathrm{p}<0.01)$ through improving fungal growth in liquid culture.
Therefore, TLM-S medium was the optimization for theophylline degradation to analyze theophylline degradation metabolites in liquid culture.

Except for caffeine, theophylline and theobromine are main purine alkaloid in tea, which both have close connection with caffeine metabolism that theophylline is catabolite of caffeine and theobromine is precursor of caffeine biosynthesis in Camellia sinensis. As mentioned above, the pathway of caffeine degradation metabolism is comparatively clear in microorganisms that both $\mathrm{N}$-demethylation and oxidation were found in caffeine degradation, and $\mathrm{N}$-demethylation was main pathway in fungi $[17,18,56]$. In addition, several bacteria and fungi have been shown to be able to utilize or degrade theobromine, which include $P$. putida, A. niger, Talaromyces marneffei, and Talaromyces verruculosus [12, 18, 20]. Mensah et al. confirmed the existence of subsequent demethylation and oxidation in theobromine degradation through the detection of correlative metabolites by HPLC under the effects of theobromine-degrading fungi [20]. However, theophylline degradation pathways and metabolites were not completely clear in fungi. In this study, it is confirmed that $A$. ustus and A. tamarii isolated from pu-erh tea could degrade theophylline in liquid culture. Based on the downstream metabolites detected in liquid culture, hypothetical theophylline degradation pathways were established and shown in Fig. 6. Both $N$-demethylation and oxidation were theophylline degradation pathways found in A. ustus and A. tamarii culture. Theophylline and related demethylated metabolites can be oxidized to 1,3-dimethyluric acid, 3-methyluric acid and uric acid, respectively. The degradation metabolites suggested the differences in degradation pathways of $A$. ustus and
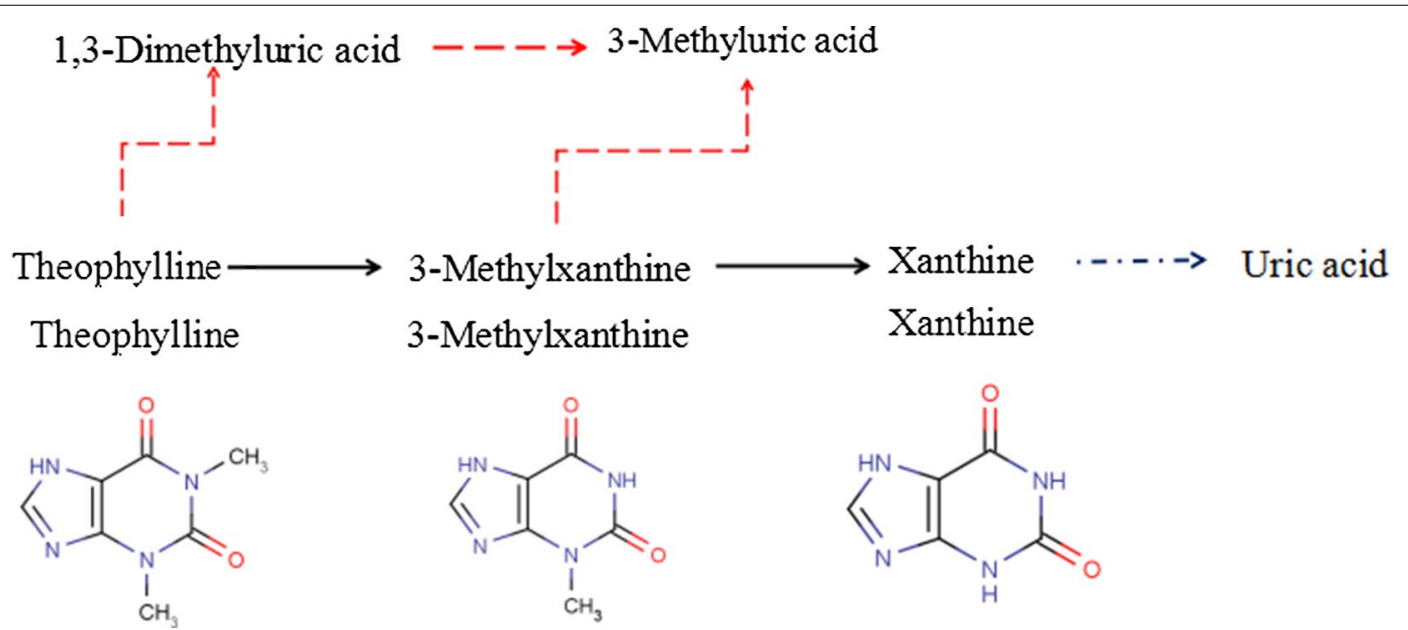

Fig. 6 Hypothetical theophylline degradation pathways employed by A. ustus and A. tamarii. The black arrows indicate the common pathways to $A$. ustus and A. tamarii. The red arrows indicate a pathway detected for A. ustus only. The blue arrows indicate a pathway detected for A. tamarii only 
A. tamari, except the common pathway that theophylline $\rightarrow$ 3-methylxanthine $\rightarrow$ xanthine. Therefore, $N$-demethylation was main theophylline degradation pathway, which was similar to caffeine and theobromine catabolism in fungi.

3-Methylxanthine and xanthine were common downstream metabolites detected in A. ustus and $A$. tamarii cultures. 3-Methylxanthine and other xanthine derivatives have been shown various biomedical effects as adenosine antagonist and inhibitors of Primary Amine Oxidase [57, 58]. Besides chemical synthesis, biotransformation and biosynthesis offered alternative way to produce 3-methylxanthine and other xanthine derivatives $[22,48]$. Due to theophylline degradation characteristic, A. ustus and $A$. tamarii would be applied in the production of 3-methylxanthine and xanthine with theophylline as feedstock through microbial conversion. The differences in accumulated concentrations of 3-methylxanthine and xanthine suggested that $A$. ustus benefits the production of 3-methylxanthine, while A. tamarii benefits the production of xanthine. After a 7-day period cultivation in $300 \mathrm{mg} / \mathrm{L}$ of TLM, A. ustus could produce $129.48 \pm 5.81 \mathrm{mg} / \mathrm{L}$ of 3-methylxanthine, and A. tamarii could produce $159.11 \pm 10.8 \mathrm{mg} / \mathrm{L}$ of xanthine, respectively.

\section{Conclusions}

This paper describes theophylline degradation pathways in tea-derived fungi and explores the application in production of methylxanthines. A. ustus and $A$. tamarii isolated from SSF of pu-erh tea and identified based on ITS, $\beta$-tubulin and calmodulin gene sequences, were confirmed to degrade theophylline significantly $(\mathrm{p}<0.01)$ in liquid culture through the sequential selections. Extensive experiments were carried out to detect related degradation metabolites by using HPLC, finding $\mathrm{N}$-demethylation and oxidation in theophylline catabolism. Through the absolute quantitative detection, it is showed that 3-methylxanthine and xanthine were main degraded metabolites in A. ustus and A. tamarii respectively, which suggests that $A$. ustus benefits the production of 3-methylxanthine, while A. tamarii benefits the production of xanthine with theophylline as feedstock. This paper also suggests theophylline degradation pathway in Aspergillus fungi and represents a new microbial synthesis platform for production of methylxanthines using theophylline through the inoculation of $A$. ustus and $A$. tamarii, respectively.

\section{Supplementary information}

Supplementary information accompanies this paper at https://doi. org/10.1186/s12934-020-01333-0.

Additional file 1: Figure S1. Colony characteristics $(a, b)$ and conidial structure (c, d) of strain PT-6. (a): Front on PDA medium at $25^{\circ} \mathrm{C}$ for 7 days. (b): Back on PDA medium at $25^{\circ} \mathrm{C}$ for 7 days. (c): Mature conidia heads, conidia stems and antipodal cells $(200 \times)$. (d): Hyohae, conidia stems and conidiums $(400 \times)$. Figure S2. Colony characteristics $(a, b)$ and conidial structure (c, d) of strain PT-7. (a): Front on PDA medium at $25^{\circ} \mathrm{C}$ for 7 days. (b): Back on PDA medium at $25^{\circ} \mathrm{C}$ for 7 days. (c): Conidia heads $(200 \times)$. (d): Conidia stems, sterigmas and conidiums $(400 \times)$. Figure S3. The received sequences of strain PT-6 (502 bp ITS sequence and 694 bp calmodulin sequence). Figure S4. The received sequences of strain PT-7 (532 bp ITS sequence, $476 \mathrm{bp} \beta$-tubulin sequence and $715 \mathrm{bp}$ calmodulin sequence). Figure S5. Neighbor-Joining consensus trees of (a) Aspergillus ustus PT-6 and (b) Aspergillus tamarii PT-7. Identification was based on ITS and calmodulin genes for A. ustus PT-6, and ITS, $\beta$-tubulin and calmodulin genes for $A$. tamarii PT-7. The numbers over branches represent bootstrap confidence values (\%) based on 1000 replicates. The scale bar denotes the nucleotide substitution per sequence.

Additional file 2: Table S1. Comparisons of fungal dry mass (mg) of each isolate in different theophylline liquid mediums after cultivation at $30^{\circ} \mathrm{C}$ for 5 days. TLM-S = theophylline liquid medium with sucrose as carbon source; TLM-D = theophylline liquid medium with dextrose with sucrose as carbon source; TLM-N = theophylline liquid medium with ammonium sulphate as nitrogen source; TLM-SN = theophylline liquid medium with sucrose and ammonium sulphate as carbon and nitrogen sources, respectively. All data were present by mean value \pm SD of three replications. The lowercase letters indicated a significant difference at $p<0.05$ levels and the uppercase letters indicated a highly significant difference at $p<0.01$ levels by using one-way ANOVA of SPSS 20.0. The different letters show significant differences of each isolate between different theophylline liquid mediums.

\section{Abbreviations}

SSF: Solid-state fermentation; CFU: Colony forming units; HPLC: High-performance liquid chromatography; PDA: Potato dextrose agar; PCR: Polymerase chain reaction; ITS: Internal transcribed spacer; dNTPS: Deoxy-ribonucleoside triphosphates; TLM: Theophylline liquid medium; TLM-S: Theophylline liquid medium with sucrose as carbon source; TLM-D: Theophylline liquid medium with dextrose as carbon source; TLM-N: Theophylline liquid medium with ammonium sulphate as nitrogen source; TLM-SN: Theophylline liquid medium with sucrose and ammonium sulphate as carbon and nitrogen sources; SPSS: Statistical product and service solutions; SD: Standard deviation; ANOVA: Analysis of variance.

\section{Acknowledgements}

We thank Yunnan University for the assistance in fungal identification.

\section{Authors' contributions}

BXZ, CQM and TX designed the study. BXZ and CQM carried out the laboratory work for the study. XHLi and CQM contributed to HPLC work. CQZ and TTW contributed to the fungal identification of the isolates. XHLiu contributed to the writing of the manuscript. All authors read and approved the final manuscript.

\section{Funding}

This work was supported by Modern Agricultural Tea Industry System of Yunnan Province, China (2017KJTX007), Modern Agricultural Industry Technology System of China (CARS-23) and National Natural Science Foundation of China (31960617). The funding bodies had no role in the design of the study, in data collection, analysis or interpretation, or in writing the manuscript. 


\section{Availability of data and materials}

The data that support the findings of this study are available from the corresponding author upon reasonable request.

\section{Ethics approval and consent to participate \\ Not applicable.}

\section{Consent for publication}

Not applicable.

\section{Competing interests}

The authors declare that they have no competing interests.

\section{Author details \\ ${ }^{1}$ Long Run Pu-erh Tea College, Yunnan Agricultural University, Kun- ming 650201, Yunnan, China. ${ }^{2}$ Kunming Dapu Tea Industry Co., LTD, Kunming 650224, Yunnan, China. ${ }^{3}$ State Key Laboratory of Tea Plant Biology and Utilization, Anhui Agricultural University, Hefei 230036, Anhui, China.}

Received: 2 December 2019 Accepted: 13 March 2020

Published online: 19 March 2020

\section{References}

1. Horzic D, Komes D, Belscak A, Ganic KK, Ivekovic D, Karlovic D. The composition of polyphenols and methylxanthines in teas and herbal infusions. Food Chem. 2009;115:441-8.

2. Mohanpuria P, Kumar $\bigvee$, Yadav SK. Tea caffeine: metabolism, functions, and reduction strategies. Food Sci Biotechnol. 2010;19:275-87.

3. Mazzafera P. Catabolism of caffeine in plants and microorganisms. J Front Biosci. 2004;9:1348-59.

4. Ashihara $\mathrm{H}$, Monteiro AM, Moritz T, Gillies FM, Crozier A Catabolism of caffeine and related purine alkaloids in leaves of Coffea arabica L. Planta. 1996:198:334-9.

5. Zhu BY, Chen LB, Lu MQ, Zhang J, Han JY, Deng WW, Zhang ZZ. Caffeine content and related gene expression: novel insight into caffeine metabolism in camellia plants containing low, normal, and high caffeine concentrations. J Agric Food Chem. 2019;2019(67):3400-11.

6. Wang W, Tang X, Hua F, Ling TJ, Wan XC, Bao GH. Camellimidazole A-C, three methylene- bridged dimeric imidazole alkaloids from Keemun black tea. Org Lett. 2018;20(9):2672-5.

7. Wang W, Zhu BY, Wang P, Deng WW, Wu GH, Wu FH, Ho CT, Liang TJ, Zhang ZZ, Wan XC, Bao GH. Enantiomeric trimethylallantoin monomers, dimers, and trimethyltriuret: evidence for an alternative catabolic pathway of caffeine in tea plant. Org Lett. 2019:21:5147-51.

8. Werner AK, Witte CP. The biochemistry of nitrogen mobilization: purine ring catabolism. Trend Plant Sci. 2011;16(7):381-7.

9. Ashihara $\mathrm{H}, \mathrm{Crozier} \mathrm{A}$. Biosynthesis and metabolism of caffeine and related purine alkaloids in plants. Adv Bot Res. 1999;30:117-205.

10. Wang LY, Wei K, Jiang YW, Cheng H, Zhou J, He W, Zhang CC. Seasonal climate effects on flavanols and purine alkaloids of tea (Camellia sinensis L.). Eur Food Res Technol. 2011:233:1049-55.

11. Zhu YC, Luo YH, Wang PP, Zhao MY, Li L, Hu XS, Chen F. Simultaneous determination of free amino acids in pu-erh tea and their changes during fermentation. Food Chem. 2016;194:643-9.

12. Yu CL, Summers RM, Li Y, Mohanty SK, Subramanian M, Pope RM. Rapid identification and quantitative validation of a caffeine-degrading pathway in Psedomonas sp. CES. J Proteome Res. 2014;14:95-106.

13. Gummadi SN, Dash SS, Devarai S. Optimization of production of caffeine demethylase by Pseudomonas sp. in a bioreactor. J Ind Microbiol Biotechnol. 2009;36:713-20.

14. Yu CL, Louie TM, Summers R, Kale Y, Gopishetty S, Subramanian M. Two distinct pathways for metabolism of theophylline and caffeine are coexpressed in Pseudomonas putida CBB5. J Bacteriol. 2009;191(14):4624-32.

15. Ma YX, Wu XH, Wu HS, Dong ZB, Ye JH, Zheng XQ, Liang YR, Lu JL. Different catabolism pathway triggered by various methylxanthines in cafffeine-tolerant bacterium Pseudomonas putida CT25 isolated from tea garden soil. J Microbiol Biotechnol. 2018;28(7):1147-55
16. Nanjundaiah S, Mutturi S, Bhatt P. Modeling of caffeine degradation kinetics during cultivation of Fusarium solani using sucrose as co-substrate. Biochem Eng J. 2017;125:73-80.

17. Hakil M, Denis S, Gonzalez GV, Augur C. Degradation and product analysis of caffeine and related dimethyl xanthine by filamentous fungi. Enzyme Microb Technol. 1998;22:355-9.

18. Brand D, Pandey A, Roussos S, Rsoccol C. Biological detoxification of coffee husk by filamentous fungi using a solid state fermentation system. Enzyme Microb Technol. 2000;27(1):127-33.

19. Dash SS, Gummadi SN. Catabolic pathways and biotechnological applications of microbial caffeine degradation. Biotechnol Lett. 2006:28:1993-2002.

20. Dash SS, Gummadi SN. Degradation kinetics of caffeine and related methylxanthines by induced cells of Pseudomonas sp. Curr Microbiol. 2007;55:56-60

21. Mensah DO, Ocloo A, Lowor ST, Bonney EY, Okine LK, Adamafio A. Isolation and characterisation of theobromine-degrading filamentous fungi. Microbiol Res. 2018:206:16-24.

22. Algharrawi KH, Summers RM, Gopishetty S, Subramanian M. Direct conversion of theophylline to 3-methylxanthine by metabolically engineered E. coli. Microb Cell Fact. 2015;14:203. https://doi.org/10.1186/s1293 4-015-0395-1.

23. Jiang HY, Shii T, Matsuo Y, Tanaka T, Jiang ZZ, Kouno I. A new catechin oxidation product and polymeric polyphenols of post-fermented tea. Food Chem. 2011:129:830-6.

24. Abe M, Takaoka N, Idemoto Y, Takagi C, Imai T, Nakasaki K. Characteristic fungi observed in the fermentation process for puer tea. Int J Food Microbiol. 2008;124:199-203.

25. Zhao M, Xiao W, Ma Y, Sun TT, Yuan WX, Na T, Zhang DL, Wang YX, Li YL, Zhou HJ, Cui XD. Structure and dynamics of the bacterial communities in fermentation of the traditional Chinese post-fermented pu-erh tea revealed by $16 \mathrm{~S}$ RNA gene clone library. World J Microb Biotechnol. 2013;29(10):1877-84.

26. Zhao M, Su XQ, Nian B, Chen $L$, Zhang DL, Duan SM, Wang LY, Shi XY, Jiang $B$, Jiang WW, Lv CY, Wang DP, Shi Y, Xiao Y, Wu JL, Pan YH, Ma Y. Integrated meta-omics approaches to understand the microbiome of spontaneous fermentation of traditional Chinese pu-erh tea. mSystems. 2019:4:e00680. https://doi.org/10.1128/msystems.00680-19.

27. Wang B. Study on the correlation between microorganism and quality formation of pu'er tea during fermentation. Earth Environ Sci. 2019;332:032055. https://doi.org/10.1088/1755-1315/332/3/032055.

28. Zhang W, Yang RJ, Fang WJ, Yan L, Lu J, Sheng J, Lv J. Characterization of thermophilic fungal community associated with pile fermentation of pu-erh tea. Int J Food Microbiol. 2016;227:29-33.

29. Wang QP, Peng CX, Gong JS. Effects of enzymatic action on the formation of theabrownin during solid state fermentation of Pu-erh tea. J Sci Food Agric. 2011;91:2412-8.

30. Zhao M, Zhang D, Su XQ, Duan SM, Wan JQ, Yuan WX, Liu BY, Ma Y, Pan $\mathrm{YH}$. An integrated metagenomics/metaproteomics investigation of the microbial communities and enzymes in solid-state fermentation of puerh tea. Sci Rep. 2015;5:10117.

31. Liang YR, Zhang LY, Lu JL. A study on chemical estimation of pu-erh tea quality. J Sci Food Agric. 2005:85:381-90.

32. Lentini A, Tabolacci C, Mattioli P, Provenzano B, Beninati S. Antitumor activity of theophylline in cobination with paclitaxel: a preclinical study on elanoma expermental lung metastasis. Cancer Biother Radiopharm. 2010;25:497-503.

33. Ma YJ, Jiang DQ, Meng JX, Li MX, Zhao HH, Wang Y, Wang LQ. Theophylline: a review of population pharmacokinetic analyses. J Clin Pharm Ther. 2016:41:594-601.

34. Shan Z, Rong W, Yang D, Yao P, Xie J, Liu L. Intravenous and nebulized magnesium sulfate for treating acute asthma in adults and children: a systematic review and meta-analysis. Respir Med. 2013;107(3):321-30.

35. Zhang L, Li N, Ma ZZ, Tu PF. Comparison of the chemical constituents of aged pu-erh tea, ripened pu-erh tea, and other teas using HPLC-DAD-ESIMS $^{n}$. J Agric Food Chem. 2011:59:8754-60.

36. Lv HP, Zhang YJ, Lin Z, Liang YR. Processing and chemical constituents of Pu-erh tea: a review. Food Res Int. 2013;53:608-18.

37. Wang D, Xiao R, Hu XT, Xu KL, Hou Y, Zhong Y, Meng J, Fan BL, Liu LG. Comparative safety evaluation of Chinese Pu-erh green tea extract 
and Pu-erh black tea extract in Wistar rats. J Agric Food Chem. 2010;58:1350-8.

38. Wang $D$, Xu KL, Zhang Y, Luo X, Xiao R, Hou Y, Bao W, Yang W, Yan H, Yao P, Liu LG. Acute and subchronic oral toxicities of Pu-erh black tea extract in Sprague-Dawley rats. J Ethnopharmacol. 2011;134:156-64.

39. Qin JH, Li N, Tu PF, Ma ZZ, Zhang L. Change in tea polyphenol and purine alkaloid composition during solid-state fungal fermentation of postfermented tea. J Agric Food Chem. 2012;60:1213-7.

40. Zhou BX, Ma CQ, Wang HZ, Xia T. Biodegradation of caffeine by whole cells of tea-derived fungi Aspergillues sydowii, Aspergillus niger and optimization for caffeine degradation. BMC Microbiol. 2018;18:53. https://doi. org/10.1186/s12866-018-1194-8.

41. Zhou BX, Ma CQ, Ren XY, Xia T, Li XH, Wu Y. Production of theophylline via aerobic fermentation of pu-erh tea using tea-derived fungi. BMC Microbial. 2019;19:261. https://doi.org/10.1186/s12866-019-1640-2.

42. Zhou BX, Ma CQ, Ren XY, Xia T, Li XH. LC-MS/MS-based metabolomic analysis of caffeine-degrading fungus Aspergillus sydowii during tea fermentation. J Food Sci. 2020;85(2):477-85.

43. Prencipe S, Siciliano I, Contessa C, Botta R, Garibaldi A, Gullino ML, Spadaro D. Characterization of Aspergillus section Flavi isolated from fresh chastnuts and along the chestnut flour process. Food Microbiol. 2018:69:159-69.

44. Wang QP, Gong JS, Chisti Y, Sirisansaneeyakul S. Fungal isolates from a pu-erh type tea fermentation and their ability to convert tea polyphenols to theabrownins. J Food Sci. 2015;80(4):M809-17.

45. Gutierrez-Sanchez G, Atwood J, Kolli VSK, Roussos S, Augur C. Initial proteome analysis of caffeine-induced proteins in Aspergillus tamari using two-dimensional fluorescence difference gel electrophoresis. Appl Biochem Biotechnol. 2012;166:2064-77.

46. Alvarenga N, Birolli WG, Seleghim Mirna HR, Porto A. Biodegradation of methyl parathion by whole cells of marine-derived fungi Aspgillus sydowi and Penicillium decaturense. Chemosphere. 2014;117:47-52.

47. Daly JW. Caffeine analogs: biomedical impact. Cell Mol Life Sci. 2007:64:2153-9.

48. Mckeague M, Wang YH, Cravens A, Win MN, Smolke CD. Engineering a microbial platform for de novo biosynthesis of diverse methylxanthins. Metab Eng. 2016;38:191-203.
49. Hollingsworth RG, Armstrong JW, Campbell E. Pest control: caffeine as a repellent for slugs and snails. Nature. 2002;417:915-6.

50. Samson RA, Visagie CM, Houbraken J, Hong SB, Hubka V, Klaassen CHW, Perrone G, Seifert KA, Susca A, Tanney JB, Varga J, Kocsube S, Szigeti G, Yaguchi T, Frisvad JC. Phylogeny, identification and nomenclature of the genus Aspergillus. Stud Mycol. 2014;78:141-73.

51. Houbraken J, Frisvad JC. Samson RA taxonomy of Penicillium section Citrina. Stud Mycol. 2011;70:53-138.

52. Tian JQ, Zhu ZX, Wu B, Wang L, Liu XZ. Bacterial and fungal communities in pu'er tea samples of different ages. J Food Sci. 2013;78(8):M1249-56.

53. Zhang YJ, Skaar I, Sulyok M, Liu XZ, Rao MY, Taylor JW. The microbiome and metabolites in fermented pu-erh tea as revealed by high-throughput sequencing and quantitative multiplex metabolite analysis. PLoS ONE. 2016;11(6):e0157847. https://doi.org/10.1371/journal.pone.0157847.

54. Zhao ZJ, Tong HR, Zhou L, Wang EX, Liu QJ. Fungal colonization of pu-erh tea in Yunnan. J Food Safety. 2010;30(4):769-84.

55. Gao L, Sun MH, Liu XZ, Che YS. Effects of carbon concentration and carbon to nitrogen ratio on the growth and sporulation of several biocontrol fungi. Mycol Res. 2007;111(1):87-92.

56. Mazzafera P, Olsson O, Sandberg G. Degradation of caffeine and related methyxanthines by Serratia marcescens isolated from soil under coffee cultivation. Microb Ecol. 1996;31:199-207.

57. Anaya AL, Cruz-Ortega R, Waller GR. Metabolism and ecology of purine alkaloids. Front Biosci. 2006;11:2354-70.

58. Shanahan P, O'Sullivan J, Tipton KF, Kinsella GK, Ryan BJ, Henehan GTM. Theobroine and related methylxanthines as inhibitors of Primary Amine Oxidase. J Food Biochem. 2019:43:e12697. https://doi.org/10.1111/ jfbc.12697.

\section{Publisher's Note}

Springer Nature remains neutral with regard to jurisdictional claims in published maps and institutional affiliations.
Ready to submit your research? Choose BMC and benefit from:

- fast, convenient online submission

- thorough peer review by experienced researchers in your field

- rapid publication on acceptance

- support for research data, including large and complex data types

- gold Open Access which fosters wider collaboration and increased citations

- maximum visibility for your research: over $100 \mathrm{M}$ website views per year

At BMC, research is always in progress.

Learn more biomedcentral.com/submissions 